\title{
ANTIOXIDANT ACTIVITY AND POLYPHENOL CONTENT IN EXTRACTS FROM VARIOUS PARTS OF FRESH AND FROZEN MANGOSTEEN
}

\author{
Anna Muzykiewicz ${ }^{1 凶}$, Joanna Zielonka-Brzezicka1 ${ }^{1}$, Joanna Siemak², \\ Adam Klimowicz ${ }^{1}$ \\ ${ }^{1}$ Chair and Department of Cosmetic and Pharmaceutical Chemistry, Pomeranian Medical University in Szczecin \\ Powstańców Wielkopolskich 72, 70-111 Szczecin, Poland \\ ${ }^{2}$ Student Research Club at the Department of Cosmetic and Pharmaceutical Chemistry, Pomeranian Medical University in Szczecin \\ Powstańców Wielkopolskich 72, 70-111 Szczecin, Poland
}

\begin{abstract}
Background. The search for new sources of natural antioxidants is very important because many diseases are caused by oxidative stress. Fruit which contain antioxidants are an important part of a healthy diet. The aim of this study was to evaluate the antioxidant activity of extracts of both the fresh and frozen peel and the flesh of Garcinia mangostana L.

Materials and methods. The extracts from the fresh and frozen peel and the flesh of mangosteen were prepared by ultrasound-assisted extraction using $20 \%, 40 \%, 70 \%$ and $96 \%(\mathrm{v} / \mathrm{v})$ ethanol for 15,30 or 60 minutes. The antioxidant potential was evaluated by the DPPH, ABTS, CUPRAC, FRAP and FIC methods, whereas the total phenolic content was measured using the Folin-Ciocalteu (F-C) technique. The contents of anthocyanins and flavonoids in the peel extracts were also determined.

Results. In most cases, the highest antioxidant activity was observed in the fresh peel samples. It was higher than the antioxidant potential of the frozen peels and the fresh and frozen flesh. The ultrasound-assisted extraction, in particular those lasting 30 or 60 minutes and using ethanol in concentrations higher than $20 \%$ $(\mathrm{v} / \mathrm{v})$, seemed to be an effective extraction process.

Conclusion. The obtained results suggest that G. mangostana, in particular its peels, could be a valuable source of antioxidants. The extraction parameters, such as the time or solvent concentration, as well as the type of plant material, had an impact on the tested properties of the extracts. However, more detailed studies on the antioxidant activity of the studied plants are required.
\end{abstract}

Keywords: Garcinia mangostana L., ultrasound-assisted extraction, plant antioxidants, freezing

\section{INTRODUCTION}

During the last few years, a lot of studies on new sources of plant antioxidants have been focused on tropical fruits and on the optimization of the extraction process to obtain the components of health-promoting activities. One such fruit is the mangosteen (Garcinia mangostana L.), which belongs to the Clusiaceae (Guttiferae) family. This evergreen tree grows in the tropical forests of Southeast Asian countries including Indonesia, Malaysia, Sri Lanka, the Philippines, Cambodia, Vietnam, Thailand and China (Guo et al., 2016; Yang et al., 2017). Mangosteen trees grow to heights of $25 \mathrm{~m}$, while its flowers are $4-5 \mathrm{~cm}$ across and are red and green (Obolskiy et al., 2009). The fruit is about $2.5-7.5 \mathrm{~cm}$ long and has a purple peel with 
a thickness of about $0.6-1.0 \mathrm{~cm}$. The edible part of the mangosteen is the pulp, which contains four to eight white segments (Akao et al., 2008). The pulp consists of water $(\sim 79.5 \%)$, carbohydrates $(\sim 17.6 \%)$, fiber $(\sim 1.77 \%)$, lipids $(\sim 0.57 \%)$, and proteins $(\sim 0.40 \%)$, as well as minerals and vitamins, mainly $\mathrm{A}$ and $\mathrm{C}$ (Devalaraja et al., 2011). The major bioactive compounds in mangosteen are xanthone and benzophenone derivatives, as well as anthocyanins. So far, over 50 xanthone derivatives, inter alia $\alpha$ - and $\gamma$-mangostin, mangostanin have been isolated from mangosteen fruit. The major benzophenones which have been isolated are garcimangosone $\mathrm{D}$, kolanon, and maclurin, while the anthocyanins are cyanidin-3-O-glucoside, cyanidin-3-O-sophoroside, and chrysanthemin. It should be emphasized that these compounds could show antioxidant activity (Devalaraja et al., 2011; Murthy et al., 2011). The peel, which is also rich in antioxidants, consists of approximately 10 phenolic acids as well as flavonoids, anthocyanins, proanthocyanidins, xanthones, and epicatechins (Suttirak and Manurakchinakorn, 2014). Due to its content of many active compounds, mangosteen has been used in traditional medicine, in particular in China, Thailand, and India. The peel has been used in the treatment of skin infections, ulcers, and dysentery, and as an antimicrobial, antiparasitic, and astringent agent. The rind decoction has been applied to treat cystitis, diarrhea, and gonorrhea (Murthy et al., 2011).

Due to its content of biologically active compounds and the growing consumption of mangosteen, the aim of this study was to evaluate the antioxidant potential of extracts prepared from the fresh and frozen pulp and peel of $G$. mangostana. The influence of solvent concentration and the time of ultrasound-assisted extraction were also assessed. Moreover, the influence of one of the most commonly used food processing methods - freezing - on the antioxidant potential of the extracts was evaluated. The content of flavonoids and anthocyanins in the peel extracts was also assessed.

\section{MATERIALS AND METHODS}

\section{Chemicals}

DPPH (2,2-diphenyl-1-picrylhydrazyl), TPTZ (2,4,6-tris(2-pyridyl)-s-triazine), ABTS (2,2'-azino-bis(3-ethylbenzothiazoline-6-sulfonic acid) and Trolox (6-hydroxy-2,5,7,8-tetramethylchromane-2-carboxy- lic acid) were purchased from Sigma-Aldrich, USA; gallic acid, Folin-Ciocalteu reagent and iron(II) sulfate heptahydrate from Merck, Germany; rutin trihydrate from Roth, Germany; ferrozine from Serva Electrophoresis, Germany; neocuproine from J\&K Scientific, Germany. Methanol, potassium persulfate, $36 \%$ hydrochloric acid, iron(III) chloride hexahydrate, 99.5\% acetic acid, sodium acetate anhydrous, sodium carbonate anhydrous, copper(II) chloride dihydrate, iron(II) chloride tetrahydrate, potassium chloride, sodium nitrite, aluminum chloride hexahydrate and sodium hydroxide were obtained from Chempur, Poland; ethanol from Linegal Chemicals, Poland. All reagents were of analytical grade.

\section{Plant material and extract preparation}

The plant material consisted of the fresh and frozen fruit flesh (pulp) and peel (pericarp) of G. mangosta$n a$. The fruit from Thailand were purchased at a local supermarket (Poland) in February 2019. Part of the material consisting of the mangosteen pulp and peel were subjected to a freezing process at a temperature of $-20^{\circ} \mathrm{C}$ and thawing at $+20^{\circ} \mathrm{C}$, just before the extraction process. The fresh and frozen material were extracted using an ultrasonic bath with a thermostat at a frequency of $40 \mathrm{kHz}$ and $250 \mathrm{~W}$ of power for 15 , 30 and 60 minutes, and $20 \%, 40 \%, 70 \%$ and $96 \%$ $(\mathrm{v} / \mathrm{v})$ ethanol as a solvent. The ultrasonic bath was set at $40^{\circ} \mathrm{C}$. To prepare the extract, solvent was added to $0.5 \mathrm{~g}$ of plant material (pulp or peel) up to $10 \mathrm{~cm}^{3}$. The obtained $5 \%(\mathrm{w} / \mathrm{v})$ extracts were stored at $+4^{\circ} \mathrm{C}$ until analysis. The spectrophotometric measurements were performed in $1 \mathrm{~cm}$ cuvettes, using a Hitachi U-5100 spectrophotometer.

\section{Antioxidant activity evaluation methods}

Evaluation of the DPPH, FRAP, ABTS and F-C methods was performed as described by Muzykiewicz et al. (2019). In the case of fresh peel and flesh, the results were calculated and expressed as $\mathrm{mg}$ of reference substance/g fresh material, whereas for frozen, they were calculated as $\mathrm{mg}$ of reference substance/g frozen material. In the DPPH and ABTS methods, the results were expressed as Trolox equivalents (TEAC) - mg Trolox/g RM (raw material), while in the FRAP technique they were expressed as $\mathrm{FeSO}_{4}$ equivalents $-\mathrm{mg} \mathrm{FeSO}_{4} / \mathrm{g}$ RM. The total polyphenol 
content, assessed using the F-C method, was shown as gallic acid (GA) equivalents (GAE) - mg GA/g RM.

The ferrous ion chelating ability (FIC) was determined according to the method of Amamra et al. (2018), with some modifications. Instead of methanol, distilled water was used to dissolve the ferrozine. The results were presented as chelating activity [\%].

The cupric reducing antioxidant capacity (CUPRAC) was evaluated according to the procedure described by Apak et al. (2004). The results were expressed as TEAC - mg Trolox/g RM.

The anthocyanin content was determined according to a protocol described by Lee et al. (2005) and expressed as cyanidin-3-glucoside [mg/L of extract].

The flavonoid content was determined following the method of Saeed et al. (2012). The results were expressed as rutin equivalents $-\mathrm{mg}$ rutin/g RM.

\section{Statistical analysis}

Three independent test samples of each extract were prepared $(n=3)$. The results were expressed as an arithmetic mean \pm standard deviation (SD). Pearson correlations $(r)$ between the results of antioxidant activity evaluated using all of the applied methods were calculated. The statistical significance of differences between the antioxidant potential of the extracts (of fresh vs. frozen raw materials) obtained via the DPPH, ABTS, CUPRAC, F-C, FIC, and FRAP methods, using the Wilcoxon signed-rank test was also evaluated ( $z$ parameter). The statistical analysis was done using Statistica 12 PL (Statsoft, Poland), assuming a significance level of $p<0.05$.

\section{RESULTS AND DISCUSSION}

The antioxidant activities of the flesh extracts determined using the DPPH, ABTS, CUPRAC, and F-C and FRAP methods are summarized in Table 1, and the antioxidant potential of the peel extracts is in Table 2. Figure 1 presents a percentage to represent the ability to chelate iron ions determined using the FIC method. The anthocyanin and flavonoid contents in the peel extracts are presented in Figure 2. The correlations between the results (both of the peel and pulp) obtained using different methods are presented in Table 3. All of them were statistically significant $(p<0.0001)$. The correlations between the antioxidant activities of the extracts prepared from fresh and frozen plant material (all the results obtained using the DPPH, ABTS, CUPRAC, FIC, F-C and FRAP methods were taken into account) as well as the differences between these parameters (Wilcoxon signed-rank test) are presented in Table 4. No significant correlations between the anthocyanin and flavonoid contents in the fresh and frozen peel extracts were observed. The differences between the activity of the extracts prepared from the fresh and frozen pulp were statistically insignificant.

G. mangostana shows antioxidant and health-promoting potential due to its content of phenolic compounds (Devalaraja et al., 2011). In our study, the evaluation of the antioxidant activity of extracts from different mangosteen parts proved their beneficial potential. All the extracts showed antioxidant properties evaluated by all of the applied methods. Higher activities were found in the peel extracts as compared to the pulp. In the case of the ABTS method, the potential of the extracts from different plant parts varied as much as twentyfold. In studies on Actinidia chinensis and Ananas comosus, Zielonka-Brzezicka et al. (2018a; 2018b) found that peel extracts showed higher antioxidant activity as compared to flesh extracts. Samuagam et al. (2015) studied the antioxidant potentials of peel extracts of rambutan, mangosteen and langsat fruit. In their study, mangosteen peel extracts showed higher properties than langsat, but lower than rambutan peel. In our study, the mangosteen pulp extracts showed significantly lower polyphenol contents than the peel extracts. The content of anthocyanins and flavonoids in the flesh extracts was at the limit of quantification. Therefore, we presented only the results of the contents of anthocyanins and flavonoids in the peel extracts. Suttirak and Manurakchinakorn (2014) emphasized that mangosteen peel is known as a source of antioxidants like phenolic acids and flavonoids.

To prepare the extracts, the flesh and peel of mangosteen were used in both forms - as fresh and frozen material. Freezing of plant material is a common and frequently used method of storage, especially shortlived materials. Freezing is a quick and controlled method to decrease the product temperature to as low as $-30^{\circ} \mathrm{C}$. This method may lead to changes in the quality of the frozen material (Fiutak et al., 2016; Paciulli et al., 2015). In this study, a higher antioxidant potential was observed for fresh material, while 
Muzykiewicz, A., Zielonka-Brzezicka, J., Siemak, J., Klimowicz, A. (2020). Antioxidant activity and polyphenol content in extracts from various parts of fresh and frozen mangosteen. Acta Sci. Pol. Technol. Aliment., 19(3), 261-270. http://dx.doi.org/10.17306/J.AFS. 2020.0788

Table 1. Antioxidant activity and total polyphenol content in flesh extracts of fresh and frozen mangosteen (mean \pm SD)

\begin{tabular}{|c|c|c|c|c|c|c|}
\hline \multirow{3}{*}{$\begin{array}{c}\text { Ethanol } \\
\text { concentration } \\
\% \mathrm{v} / \mathrm{v}\end{array}$} & \multicolumn{4}{|c|}{ Fresh flesh } & \multicolumn{2}{|l|}{ Frozen flesh } \\
\hline & \multicolumn{6}{|c|}{ extraction time, $\min$} \\
\hline & 15 & 30 & 60 & 15 & 30 & 60 \\
\hline \multicolumn{7}{|c|}{ DPPH, mg Trolox/g RM } \\
\hline 20 & $0.66 \pm 0.03$ & $0.70 \pm 0.08$ & $0.83 \pm 0.07$ & $0.43 \pm 0.01$ & $0.55 \pm 0.03$ & $0.52 \pm 0.01$ \\
\hline 40 & $0.67 \pm 0.08$ & $0.60 \pm 0.01$ & $0.70 \pm 0.02$ & $0.57 \pm 0.02$ & $0.44 \pm 0.03$ & $0.83 \pm 0.06$ \\
\hline 70 & $0.12 \pm 0.01$ & $0.57 \pm 0.04$ & $1.15 \pm 0.09$ & $0.67 \pm 0.06$ & $0.58 \pm 0.04$ & $0.56 \pm 0.02$ \\
\hline 96 & $0.40 \pm 0.02$ & $0.66 \pm 0.01$ & $0.52 \pm 0.07$ & $0.50 \pm 0.01$ & $0.65 \pm 0.03$ & $0.66 \pm 0.03$ \\
\hline \multicolumn{7}{|c|}{ ABTS, mg Trolox/g RM } \\
\hline 20 & $0.69 \pm 0.03$ & $0.84 \pm 0.06$ & $1.41 \pm 0.04$ & $0.64 \pm 0.13$ & $1.60 \pm 0.15$ & $1.00 \pm 0.08$ \\
\hline 40 & $1.06 \pm 0.02$ & $0.59 \pm 0.01$ & $1.14 \pm 0.01$ & $1.46 \pm 0.13$ & $1.17 \pm 0.00$ & $2.19 \pm 0.10$ \\
\hline 70 & $0.72 \pm 0.05$ & $0.63 \pm 0.02$ & $2.69 \pm 0.12$ & $1.73 \pm 0.06$ & $1.43 \pm 0.15$ & $1.07 \pm 0.03$ \\
\hline 96 & $0.78 \pm 0.01$ & $0.59 \pm 0.01$ & $0.93 \pm 0.07$ & $0.94 \pm 0.08$ & $2.03 \pm 0.13$ & $1.57 \pm 0.02$ \\
\hline \multicolumn{7}{|c|}{ CUPRAC, mg Trolox/g RM } \\
\hline 20 & $0.03 \pm 0.00$ & $0.06 \pm 0.01$ & $1.44 \pm 0.16$ & $0.30 \pm 0.03$ & $0.60 \pm 0.01$ & $0.88 \pm 0.10$ \\
\hline 40 & $0.06 \pm 0.01$ & $0.13 \pm 0.00$ & $2.41 \pm 0.24$ & $0.68 \pm 0.03$ & $0.11 \pm 0.03$ & $2.75 \pm 0.16$ \\
\hline 70 & $0.03 \pm 0.01$ & $0.18 \pm 0.01$ & $4.42 \pm 0.06$ & $0.09 \pm 0.01$ & $0.32 \pm 0.07$ & $0.53 \pm 0.01$ \\
\hline 96 & $1.18 \pm 0.02$ & $0.04 \pm 0.01$ & $1.43 \pm 0.17$ & $0.81 \pm 0.06$ & $0.88 \pm 0.04$ & $1.34 \pm 0.12$ \\
\hline \multicolumn{7}{|c|}{ Folin-Ciocalteu, mg GA/g RM } \\
\hline 20 & $0.54 \pm 0.05$ & $0.56 \pm 0.06$ & $0.84 \pm 0.07$ & $0.24 \pm 0.00$ & $0.40 \pm 0.02$ & $0.65 \pm 0.05$ \\
\hline 40 & $0.75 \pm 0.08$ & $1.22 \pm 0.19$ & $0.81 \pm 0.02$ & $0.51 \pm 0.01$ & $0.31 \pm 0.02$ & $1.09 \pm 0.02$ \\
\hline 70 & $1.59 \pm 0.07$ & $1.83 \pm 0.07$ & $1.05 \pm 0.14$ & $0.38 \pm 0.00$ & $0.42 \pm 0.04$ & $0.41 \pm 0.01$ \\
\hline 96 & $1.36 \pm 0.12$ & $1.67 \pm 0.10$ & $1.30 \pm 0.12$ & $0.27 \pm 0.04$ & $0.48 \pm 0.01$ & $0.67 \pm 0.07$ \\
\hline \multicolumn{7}{|c|}{ FRAP, $\mathrm{mg} \mathrm{FeSO}_{4} / \mathrm{g} \mathrm{RM}$} \\
\hline 20 & $0.50 \pm 0.02$ & $0.59 \pm 0.06$ & $1.14 \pm 0.01$ & $0.44 \pm 0.00$ & $0.68 \pm 0.04$ & $0.71 \pm 0.03$ \\
\hline 40 & $0.60 \pm 0.01$ & $0.63 \pm 0.01$ & $1.14 \pm 0.05$ & $0.67 \pm 0.04$ & $0.53 \pm 0.06$ & $1.41 \pm 0.02$ \\
\hline 70 & $0.61 \pm 0.02$ & $0.57 \pm 0.02$ & $2.36 \pm 0.05$ & $0.81 \pm 0.01$ & $0.79 \pm 0.09$ & $0.93 \pm 0.01$ \\
\hline 96 & $0.88 \pm 0.02$ & $0.53 \pm 0.01$ & $0.85 \pm 0.01$ & $0.56 \pm 0.03$ & $0.87 \pm 0.03$ & $1.13 \pm 0.01$ \\
\hline
\end{tabular}

in the group of peel extracts, the opposite results were found for activity evaluated by applying the DPPH and FRAP methods, where the highest potential was found for extracts of frozen $G$. mangostana parts. The highest polyphenol content was also detected in extracts prepared from fresh plant material. Złotek et al. (2016) compared the total polyphenol content in basil leaf extracts (F-C method) as well as their antioxidant activity, which was evaluated using the DPPH technique. They also obtained higher properties in the 
Muzykiewicz, A., Zielonka-Brzezicka, J., Siemak, J., Klimowicz, A. (2020). Antioxidant activity and polyphenol content in extracts from various parts of fresh and frozen mangosteen. Acta Sci. Pol. Technol. Aliment., 19(3), 261-270. http://dx.doi.org/10.17306/J.AFS. 2020.0788

Table 2. Antioxidant activity and total polyphenol content in peel extracts of fresh and frozen mangosteen (mean \pm SD)

\begin{tabular}{|c|c|c|c|c|c|c|}
\hline \multirow{3}{*}{$\begin{array}{c}\text { Ethanol } \\
\text { concentration } \\
\% \mathrm{v} / \mathrm{v}\end{array}$} & \multicolumn{3}{|c|}{ Fresh peel } & \multicolumn{3}{|c|}{ Frozen peel } \\
\hline & \multicolumn{6}{|c|}{ extraction time, $\min$} \\
\hline & 15 & 30 & 60 & 15 & 30 & 60 \\
\hline \multicolumn{7}{|c|}{ DPPH, mg Trolox/g RM } \\
\hline 20 & $4.03 \pm 0.11$ & $4.05 \pm 0.07$ & $4.21 \pm 0.01$ & $4.23 \pm 0.01$ & $4.26 \pm 0.01$ & $4.41 \pm 0.01$ \\
\hline 40 & $4.28 \pm 0.02$ & $4.28 \pm 0.03$ & $4.26 \pm 0.04$ & $4.43 \pm 0.02$ & $4.52 \pm 0.01$ & $4.25 \pm 0.01$ \\
\hline 70 & $4.29 \pm 0.07$ & $4.30 \pm 0.05$ & $4.62 \pm 0.03$ & $4.55 \pm 0.02$ & $4.48 \pm 0.02$ & $4.60 \pm 0.02$ \\
\hline 96 & $4.17 \pm 0.06$ & $4.38 \pm 0.01$ & $4.61 \pm 0.04$ & $4.49 \pm 0.05$ & $4.65 \pm 0.01$ & $4.50 \pm 0.03$ \\
\hline \multicolumn{7}{|c|}{ ABTS, mg Trolox/g RM } \\
\hline 20 & $12.58 \pm 0.12$ & $13.87 \pm 0.21$ & $18.24 \pm 0.04$ & $12.97 \pm 0.09$ & $14.84 \pm 0.06$ & $17.05 \pm 0.31$ \\
\hline 40 & $16.59 \pm 0.18$ & $16.52 \pm 0.09$ & $17.99 \pm 0.04$ & $14.93 \pm 0.10$ & $17.04 \pm 0.28$ & $14.29 \pm 0.30$ \\
\hline 70 & $56.26 \pm 1.83$ & $47.61 \pm 1.02$ & $56.54 \pm 1.79$ & $16.76 \pm 0.37$ & $18.30 \pm 0.01$ & $17.85 \pm 0.05$ \\
\hline 96 & $15.93 \pm 0.57$ & $17.70 \pm 0.05$ & $17.17 \pm 0.38$ & $14.76 \pm 0.06$ & $18.32 \pm 0.01$ & $15.99 \pm 0.13$ \\
\hline \multicolumn{7}{|c|}{ CUPRAC, mg Trolox/g RM } \\
\hline 20 & $5.36 \pm 0.17$ & $5.69 \pm 0.19$ & $4.88 \pm 0.13$ & $4.90 \pm 0.01$ & $4.94 \pm 0.16$ & $5.12 \pm 0.28$ \\
\hline 40 & $5.02 \pm 0.00$ & $5.36 \pm 0.14$ & $5.02 \pm 0.14$ & $5.26 \pm 0.08$ & $5.33 \pm 0.21$ & $5.00 \pm 0.12$ \\
\hline 70 & $4.95 \pm 0.20$ & $5.02 \pm 0.01$ & $5.10 \pm 0.05$ & $5.23 \pm 0.03$ & $5.18 \pm 0.39$ & $5.02 \pm 0.05$ \\
\hline 96 & $4.80 \pm 0.16$ & $4.88 \pm 0.10$ & $4.84 \pm 0.19$ & $5.13 \pm 0.12$ & $5.20 \pm 0.11$ & $5.50 \pm 0.43$ \\
\hline \multicolumn{7}{|c|}{ Folin-Ciocalteu, mg GA/g RM } \\
\hline 20 & $7.49 \pm 0.34$ & $8.85 \pm 0.06$ & $11.59 \pm 0.25$ & $7.33 \pm 0.07$ & $8.31 \pm 0.04$ & $8.33 \pm 0.17$ \\
\hline 40 & $10.22 \pm 0.31$ & $11.03 \pm 0.25$ & $11.40 \pm 0.35$ & $8.50 \pm 0.23$ & $8.99 \pm 0.05$ & $7.45 \pm 0.07$ \\
\hline 70 & $11.53 \pm 0.29$ & $11.24 \pm 0.40$ & $11.68 \pm 0.10$ & $8.78 \pm 0.12$ & $10.07 \pm 0.02$ & $9.26 \pm 0.18$ \\
\hline 96 & $9.92 \pm 0.18$ & $11.46 \pm 0.10$ & $12.16 \pm 0.13$ & $8.34 \pm 0.11$ & $10.12 \pm 0.06$ & $8.57 \pm 0.04$ \\
\hline \multicolumn{7}{|c|}{ FRAP, $\mathrm{mg} \mathrm{FeSO}_{4} / \mathrm{g} \mathrm{RM}$} \\
\hline 20 & $9.69 \pm 0.01$ & $12.75 \pm 0.25$ & $16.17 \pm 0.25$ & $12.36 \pm 0.18$ & $14.57 \pm 0.02$ & $14.42 \pm 0.52$ \\
\hline 40 & $13.41 \pm 0.48$ & $14.98 \pm 0.21$ & $14.94 \pm 0.51$ & $12.48 \pm 0.46$ & $14.82 \pm 0.05$ & $10.60 \pm 0.01$ \\
\hline 70 & $15.91 \pm 0.17$ & $15.54 \pm 0.22$ & $17.45 \pm 0.24$ & $14.84 \pm 0.32$ & $15.45 \pm 0.29$ & $17.70 \pm 0.42$ \\
\hline 96 & $14.24 \pm 0.35$ & $17.37 \pm 0.26$ & $15.51 \pm 0.52$ & $13.50 \pm 0.35$ & $15.15 \pm 0.42$ & $15.05 \pm 0.19$ \\
\hline
\end{tabular}

case of fresh material samples. Moreover, they found a statistically significant correlation between the polyphenol content and the antioxidant activity of the extracts. Similar observations were noticed in our own study.
In our study, extracts were obtained using the socalled green extraction technique, based on the application of ultrasounds. As solvents, aqueous solutions of ethanol at concentrations 20, 40, 70 and 96\% were applied. The extraction process was carried out for 15 , 

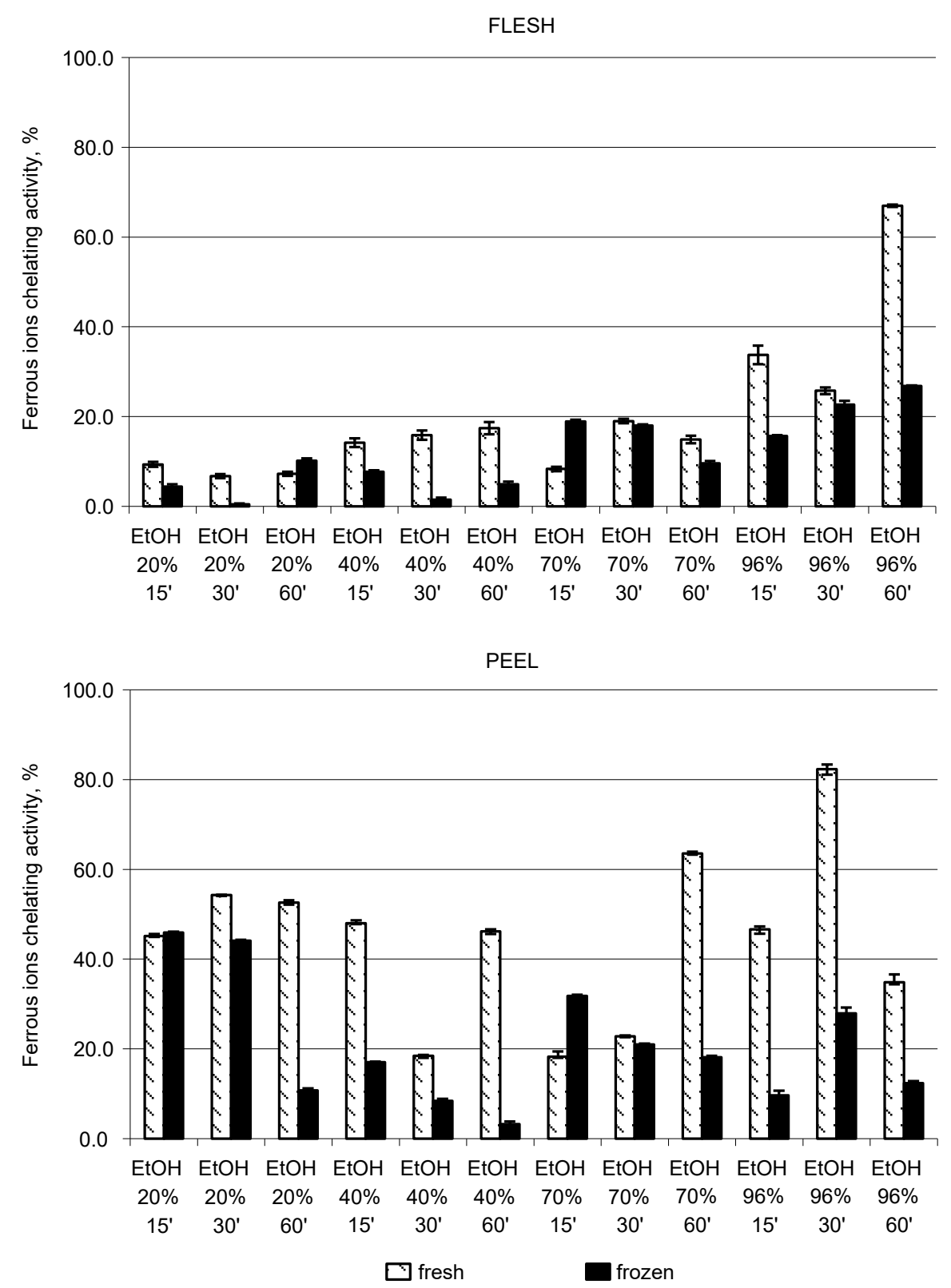

Fig. 1. The percentage ability to chelate iron ions determined by the FIC method. Vertical lines represent standard deviations

30 and 60 minutes. The choice of a proper extraction method and its parameters i.e. time and solvent, are important factors in obtaining valuable extracts. In our study, the higher activities evaluated using all of the applied methods were found mainly for extracts prepared in $70 \%$ ethanol for 60 minutes for fresh material, in $40 \%$ for 60 minutes for frozen fruit flesh, and in $96 \%$ ethanol for 30 or 60 minutes for the frozen peel. The lowest concentration of solvent and the shortest extraction time seemed not to be as effective. Many authors have emphasized the influence of solvent concentration on the ability to extract the biologically active 

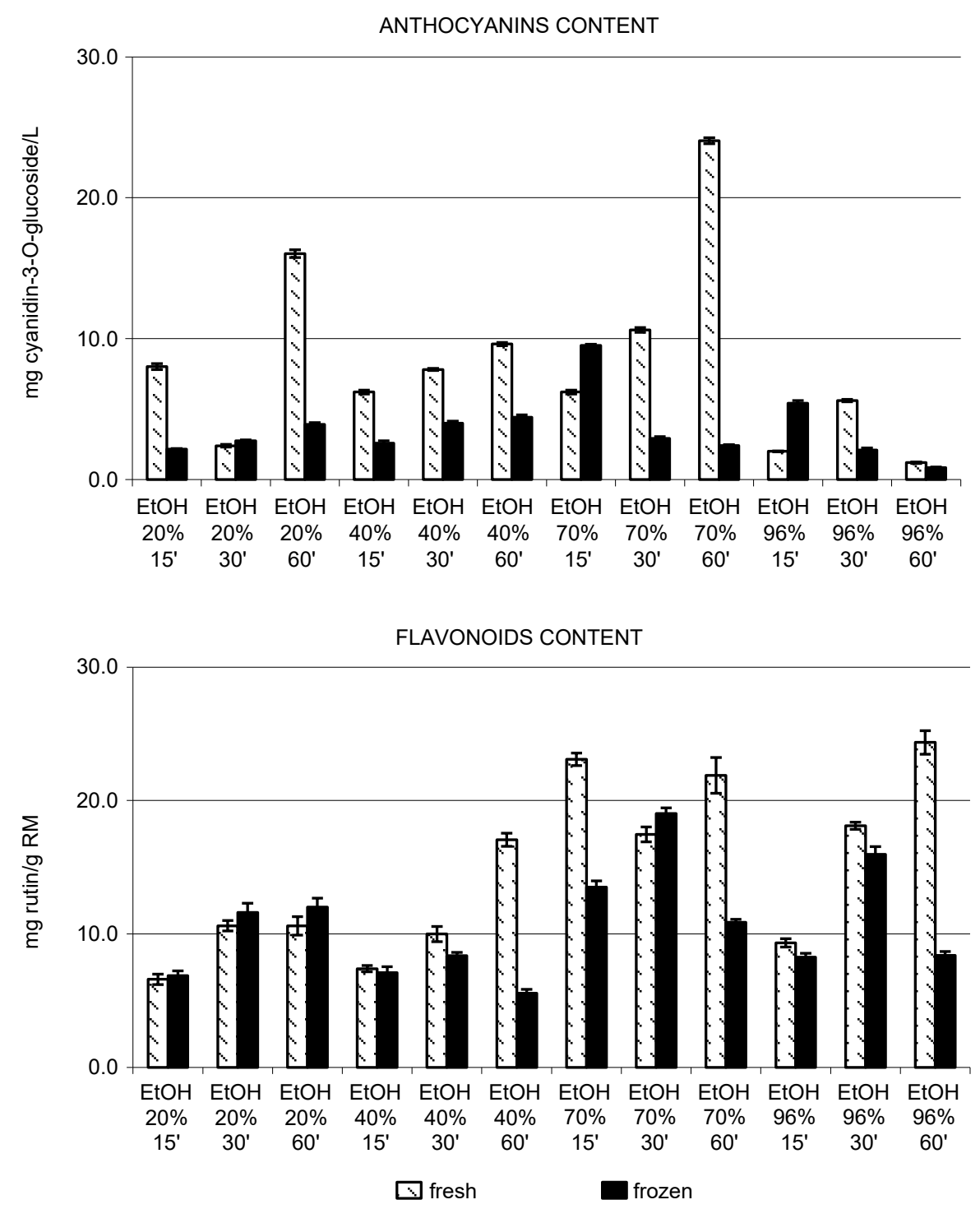

Fig. 2. The anthocyanin and flavonoid contents in the peel extracts. Vertical lines represent standard deviations

compounds, including those with antioxidant potential. $\mathrm{Xu}$ et al. (2017) focused on extraction methods as well as their conditions and concluded that the selection of solvents should be based on the polarity and chemical nature of the antioxidants to be extracted. In our study, we noticed that $70 \%$ and $96 \%$ ethanol were more effective in extracts of peel (both fresh and frozen) and fresh flesh, whereas the $40 \%$ alcohol was more effective in preparing extracts of frozen flesh. Spigno et al. (2007), in their grape research, noticed that the phenol yield extraction increased with the water content of ethanol from $10 \%$ to $30 \%$, whereas the phenol concentration of extracts decreased with water content above $50 \%$. This could explain why ethanol in concentrations of $70 \%$ and $96 \%$ was more effective in the extraction of the mangosteen peels, which are the valuable source of phenolic compounds. Ahmad-Qasem et al. (2013) studied the effects of freezing on the antioxidant activity and 
Muzykiewicz, A., Zielonka-Brzezicka, J., Siemak, J., Klimowicz, A. (2020). Antioxidant activity and polyphenol content in extracts from various parts of fresh and frozen mangosteen. Acta Sci. Pol. Technol. Aliment., 19(3), 261-270. http://dx.doi.org/10.17306/J.AFS. 2020.0788

Table 3. Correlation coefficients between antioxidant activities obtained by different methods

\begin{tabular}{|c|c|c|c|c|c|}
\hline & ABTS & FRAP & F-C & FIC & CUPRAC \\
\hline DPPH & $0.747 *$ & $0.985^{*}$ & $0.969 *$ & $0.427 *$ & $0.953^{*}$ \\
\hline ABTS & & $0.787^{*}$ & $0.803^{*}$ & $0.359^{*}$ & $0.698^{*}$ \\
\hline FRAP & & & $0.983^{*}$ & $0.467^{*}$ & $0.932 *$ \\
\hline F-C & & & & $0.259^{*}$ & $0.912^{*}$ \\
\hline FIC & & & & & $0.429^{*}$ \\
\hline
\end{tabular}

$*_{p}<0.05$.

Table 4. Statistical analysis of the differences and correlations between the antioxidant potential of extracts of fresh and frozen parts of mangosteen fruit

\begin{tabular}{lcc}
\hline \multicolumn{1}{c}{ Part of mangosteen fruit } & Differences & Corellation coefficient \\
\hline Fresh peel vs. frozen peel & $z=3.827 ; p<0.001$ & $r=0.627 ; p<0.001$ \\
Fresh pulp vs. frozen pulp & NS & $r=0.856 ; p<0.001$ \\
Fresh peel vs. fresh pulp & $z=7.020 ; p<0.001$ & $r=0.510 ; p<0.001$ \\
Frozen peel vs. frozen pulp & $z=6.852 ; p<0.001$ & $r=0.356 ; p<0.010$ \\
\hline
\end{tabular}

NS - not statistically significant $(p>0.05)$.

the phenolic compound content in olive extracts and found that this process affects the decrease of phenolic compounds in the tested plant material. In our study, we also noticed higher contents of total polyphenols in the fresh raw material, in particular in the peel extracts. Therefore, in the case of frozen pulp, $40 \%$ ethanol was more effective as an extractant. Zielonka-Brzezicka et al. (2018a; 2018b), in their studies on Actinidia chinensis and Ananas comosus, also found $70 \%$ ethanol to be the most suitable solvent to obtain extracts with antioxidant potential. Vichit and Saewan (2019) extracted peanut callus in $0,25,50,70$ and $95 \%(\mathrm{v} / \mathrm{v})$ ethanol and found the highest phenolic content and antioxidant potential of extracts with $95 \%$ ethanol using different analytical methods. Moreover, Muzykiewicz et al. (2018) evaluated the antioxidant activity of sea buckthorn extracts and came to the conclusion that the longest time of ultrasound-assisted extraction resulted in the highest activity of the obtained extracts, while the lowest results were obtained for samples prepared during the shortest extraction process. Chemat et al. (2011) classified ultrasound extraction in the group of "green" separation techniques. Ultrasound waves can change the chemical and physical properties of extracted plant material and the cavitational effect facilitates the release of extractable compounds by disrupting the plant cell walls. Compared to conventional extraction methods such as Soxhlet extraction, maceration, or steam distillation, ultrasound-assisted extraction allows a reduction of the extraction time and the amount of solvent to be used. Moreover, the final extraction products are characterized by higher purity. Azwanida (2015) reported that using ultrasound of a frequency higher than $20 \mathrm{kHz}$ could lead to free radical formation followed by their reaction with active phytochemicals. It should be emphasized that ultrasound-assisted extraction has been used by many researchers to isolate active compounds and those with antioxidant potential from mangosteen. Hiranrangsee et al. (2016) extracted anthocyanins from the pericarp, while Cheok et al. (2013) optimized the ultrasound extraction process of anthocyanins and phenolic compounds from mangosteen hull. Taking into account the extraction of specific plant material, it should be considered that there 
is no universal extraction method and each procedure is unique and depends on certain factors such as the compounds of interest to be extracted.

\section{CONCLUSIONS}

The mangosteen fruit seems to be a valuable source of antioxidants. Markedly higher antioxidant properties were found in the peel extracts due to the presence of a few groups of antioxidants. Freezing the plant material before the extraction had an impact on the antioxidant activity of the extracts. On the whole, the extracts prepared from frozen material had a lower antioxidant potential and polyphenol content, including anthocyanins and flavonoids. Our results suggest the possibility to apply ethanolic peel extracts as a valuable source of antioxidants, particularly those prepared using an ethanol concentration exceeding 20\% (v/v). A prolonged extraction time of up to one hour could also enhance the antioxidant activity of extracts.

\section{REFERENCES}

Ahmad-Qasem, M. H., Barrajón-Catalán, E., Micol, V., Mulet, A., García-Pérez, J. V. (2013). Influence of freezing and dehydration of olive leaves (var. Serrana) on extract composition and antioxidant potential. Food Res. Int., 50(1), 189-196. https://doi.org/10.1016/j. foodres.2012.10.028

Akao, Y., Nakagawa, Y., Iinuma, M., Nozawa, Y. (2008). Anti-cancer effects of Xanthones from pericarps of mangosteen. Int. J. Mol. Sci., 9(3), 355-370. https://doi. org/10.3390/ijms 9030355

Amamra, S., Cartea, M. E., Belhaddad, O. E., Soengas, P., Abderrahmane, B., Kaabi, I., Arrar, L. (2018). Determination of total phenolics contents, antioxidant capacity of Thymus vulgaris extracts using electrochemical and spectrophotometric methods. Int. J. Electrochem. Sci., 13, 7882-7893. https://dx.doi.org/10.20964/2018.08.57

Apak, R., Güçlü, K., Özyürek, M., Karademir, S. E. (2004). Novel total antioxidant capacity index for dietary polyphenols and vitamins $\mathrm{C}$ and $\mathrm{E}$, using their cupric ion reducing capability in the presence of neocuproine: CUPRAC method. J. Agric. Food Chem., 52(26), 7970 7981. https://doi.org/10.1021/jf048741x

Azwanida, N. N. (2015). A review on the extraction methods use in medicinal plants, principle, strength and limitation. Med. Aromat. Plants, 4(3), 3-8.
Chemat, F., Zill-e-Huma, M., Khan, M. K. (2011). Applications of ultrasound in food technology: Processing, preservation and extraction. Ultrason. Sonochem., 18(4), 813-835. https://doi.org/10.1016/j. ultsonch.2010.11.023

Cheok, C. Y., Chin, N. L., Yusof, Y. A., Talib, R. A., Law, C. L. (2013). Optimization of total monomeric anthocyanin (TMA) and total phenolic content (TPC) extractions from mangosteen (Garcinia mangostana Linn.) hull using ultrasonic treatments. Ind. Crops Prod., 50, 1-7. http://dx.doi.org/10.1016/j.indcrop.2013.07.024

Devalaraja, S., Jain, S., Yadav, H. (2011). Exotic fruits as therapeutic complements for diabetes, obesity and metabolic syndrome. Food Res. Int., 44(7), 1856-1865. https://dx.doi.org/10.1016/j.foodres.2011.04.008

Fiutak, G., Hajduk, E., Filipczak-Fiutak, M., Macura, M., Firek, B. (2016). Wpływ wybranych procesów termicznych na zachowanie właściwości przeciwutleniających homogenatów z owoców jagodowych [Effect of selected thermal processes on antioxidant properties of berry fruit homogenates]. Żywn. Nauka Technol. Jakość, 23, 2(105), 106-117. [in Polish]. https://dx.doi. org/10.15193/zntj/2016/105/119

Guo, M., Wang, X., Lu, X., Wang, H., Brodelius, P. E. (2016). $\alpha$-Mangostin extraction from the native mangosteen (Garcinia mangostana L.) and the binding mechanisms of $\alpha$-mangostin to HSA or TRF. PLoS One, 11, 1-22. https://dx.doi.org/10.1371/journal.pone.0161566

Hiranrangsee, L., Kumaree, K. K., Sadiq, M. B., Anal, A. K. (2016). Extraction of anthocyanins from pericarp and lipids from seeds of mangosteen (Garcinia mangostana L.) by Ultrasound-assisted extraction (UAE) and evaluation of pericarp extract enriched functional ice-cream. J. Food Sci. Technol., 53(10), 3806-3813. http://dx.doi. org/ 10.1007/s13197-016-2368-8

Lee, J., Durst, R. W., Wrolstad, R. E. (2005). Determination of total monomeric anthocyanin pigment content of fruit juices, beverages, natural colorants, and wines by the $\mathrm{pH}$ differential method: collaborative study. J. AOAC Int., 88(5), 1269-1278.

Murthy, H. N., Dandin, V. S., Dalawai, D., Park, S. Y., Paek, K. Y. (2018). Bioactive compounds from Garcinia fruits of high economic value for food and health. In J. M. Mérillon, K. G. Ramawat (Eds.), Bioactive molecules in food (pp. 1643-1670). Reference Series in Phytochemistry. Cham: Springer. https://doi.org/10.1007/978-3319-78030-6_65

Muzykiewicz, A., Zielonka-Brzezicka, J., Klimowicz, A. (2018). Antioxidant potential of Hippophae rhamnoides L. extracts obtained with green extraction technique. 
Herba Pol., 64(4), 14-22. https://dx.doi.org/10.2478/ hepo-2018-0022

Muzykiewicz, A., Zielonka-Brzezicka, J., Klimowicz, A. (2019). The antioxidant potential of flesh, albedo and flavedo extracts from different varieties of grapefruits. Acta. Sci. Pol. Technol.Aliment., 18(4), 453-462.https:// dx.doi.org/10.17306/J.AFS.2019.0731

Obolskiy, D., Pischel, I., Siriwatanametanon, N., Heinrich, M. (2009). Garcinia mangostana L.: a phytochemical and pharmacological review. Phytother. Res., 23(8), 1047-1065. https://dx.doi.org/10.1002/ptr.2730

Paciulli, M., Ganino, T., Pellegrini, N., Rinaldi, M., Zaupa, M., Fabbri, A., Chiavaro, E. (2015). Impact of the industrial freezing process on selected vegetables - Part I. Structure, texture and antioxidant capacity. Food Res. Int., 74, 329-337. https://dx.doi.org/10.1016/j. foodres.2014.04.019

Saeed, N., Khan, M. R., Shabbir, M. (2012). Antioxidant activity, total phenolic and total flavonoid contents of whole plant extracts Torilis leptophylla L. BMC Compl. Alternative Med., 12(1), 221.

Samuagam, L., Sia, M. C., Akowuah, G. A., Okechukwu, P. N., Yim, H. S. (2015). In vivo antioxidant potentials of rambutan, mangosteen, and langsat peel extracts and effects on liver enzymes in experimental rats. J. Food Sci. Biotechnol., 24(1), 191-198. https://dx.doi.org/10.1007/ s10068-015-0026-y

Spigno, G., Tramelli, L., De Faveri, D. M. (2007). Effects of extraction time, temperature and solvent on concentration and antioxidant activity of grape marc phenolics. J. Food Eng., 81(1), 200-208. https://doi.org/10.1016/j. jfoodeng.2006.10.021

Suttirak, W., Manurakchinakorn, S. (2014). In vitro antioxidant properties of mangosteen peel extract. J.
Food Sci. Technol., 51(12), 3546-3558. https://dx.doi. org/10.1007/s13197-012-0887-5

Vichit, W., Saewan, N. (2019). In vitro antioxidant activities and cytotoxicity of peanut callus extract. Food Appl. Biosci. J., 7(3), 142-151.

Xu, D. P., Li, Y., Meng, X., Zhou, T., Zhou, Y., Zheng, J., ..., Li, H. B. (2017). Natural antioxidants in foods and medicinal plants: extraction, assessment and resources. Int. J. Mol. Sci., 18(1), 1-32. https://dx.doi.org/10.3390/ ijms 18010096

Yang, R., Li, P., Li, N., Zhang, Q., Bai, X., Wang, L., ..., Yan, J. (2017). Xanthones from the pericarp of Garcinia mangostana. Molecules, 22(5), 683. https://dx.doi. org/10.3390/molecules22050683

Zielonka-Brzezicka, J., Nowak, A., Klimowicz, A., Wira, D., Grzesiak, K., Rędzikowska, E., ..., Bilska, J. (2018a). Aktinidia chińska jako źródło prozdrowotnych antyoksydantów [Actinidia chinensis as a source of healthpromoting antioxidants]. Probl. Hig. Epidemiol., 99(3), 238-244 [in Polish].

Zielonka-Brzezicka, J., Nowak, A., Klimowicz, A., Duchnik, W., Wira, D., Wysocka, D., ..., Bilska, J. (2018b). Ocena aktywności antyoksydacyjnej ananasa jadalnego (Ananas comosus) [Evaluation of the antioxidant activity of pineapple (Ananas comosus)]. Pomeranian J. Life Sci., 64(3), 132-138 [in Polish].

Złotek, U., Mikulska, S., Nagajek, M., Świeca, M. (2016). The effect of different solvents and number of extraction steps on the polyphenol content and antioxidant capacity of basil leaves (Ocimum basilicum L.) extracts. Saudi J. Biol. Sci., 23(5), 628-633. https://doi.org/10.1016/j. sjbs.2015.08.002 